\title{
FLOW-REGIME CHARACTERIZATION FOR HORIZONTAL TWO-PHASE STEAM FLOW
}

\author{
Clarence A. Calder
}

October 5, 1976

\section{MASTER}

Prepared for U.S. Energy Research \& Development Administration under contract No. W-7405-Eng-48

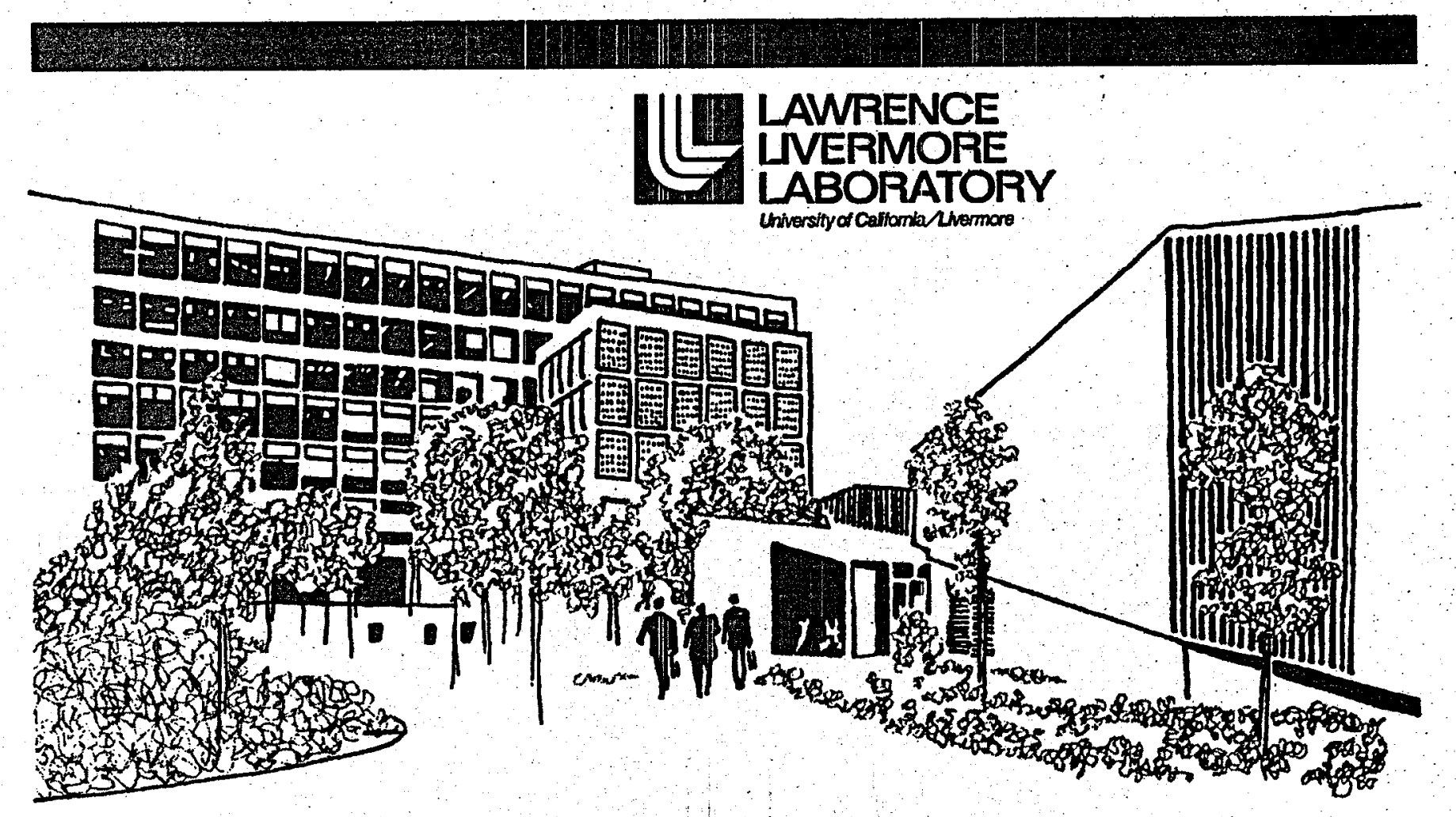




\section{DISCLAIMER}

This report was prepared as an account of work sponsored by an agency of the United States Government. Neither the United States Government nor any agency Thereof, nor any of their employees, makes any warranty, express or implied, or assumes any legal liability or responsibility for the accuracy, completeness, or usefulness of any information, apparatus, product, or process disclosed, or represents that its use would not infringe privately owned rights. Reference herein to any specific commercial product, process, or service by trade name, trademark, manufacturer, or otherwise does not necessarily constitute or imply its endorsement, recommendation, or favoring by the United States Government or any agency thereof. The views and opinions of authors expressed herein do not necessarily state or reflect those of the United States Government or any agency thereof. 


\section{DISCLAIMER}

Portions of this document may be illegible in electronic image products. Images are produced from the best available original document. 
This report was prepared as an account of work sponsored by the United States Government. Neither the United States nor the United States Energy Research \& Development Administration, nor any of their employees, nor any of their contractors, subcontractors, or their employees, makes any warranty, express or implied, or assumes any legal liability or responsibility for the accuracy, completeness or usefulness of any information, apparatus, product or process disclosed, or represents that its use would not infringe privately-owned rights.

\section{NOTICE}

Reference to a company or product name does not imply approval or recommendation of the product by the University of California or the U.S. Energy Research \& Development Administration to the exclusion of others that may be stitable.

Printed in the United States of America Available from

National Technical Information Service

U.S. Department of Commerce

5285 Port Royal Road

Springfield, VA 22161

Price: Printed Copy \$ ; Microfiche $\$ 3.00$

\begin{tabular}{ccccc} 
Page Range & $\begin{array}{c}\text { Domestic } \\
\text { Price }\end{array}$ & $\begin{array}{c}\text { Page Range } \\
\text { y }\end{array}$ & $\begin{array}{c}\text { Domestic } \\
\text { Price }\end{array}$ \\
\hline $001-025$ & 53.50 & $326-350$ & 10.00 \\
$026-050$ & 4.00 & $351-375$ & 10.50 \\
$051-075$ & 4.50 & $376-400$ & 10.75 \\
$076-100$ & 5.00 & $401-425$ & 11.00 \\
$101-125$ & 5.50 & $426-450$ & 11.75 \\
$126-150$ & 6.00 & $451-475$ & 12.00 \\
$151-175$ & 6.75 & $476-500$ & 12.50 \\
$176-200$ & 7.50 & $501-525$ & 12.75 \\
$201-225$ & 7.75 & $526-550$ & 13.00 \\
$226-250$ & 8.00 & $551-575$ & 13.50 \\
$251-275$ & 9.00 & $576-600$ & 13.75 \\
$276-300$ & 9.25 & $601-40$ & \\
$301-325$ & 9.75 & & \\
& & &
\end{tabular}

Add $\$ 2.50$ for each additional 100 page increment from 601 to 1,000 pages; add \$4.50 for each additional 100 page increment over 1,000 pages. 


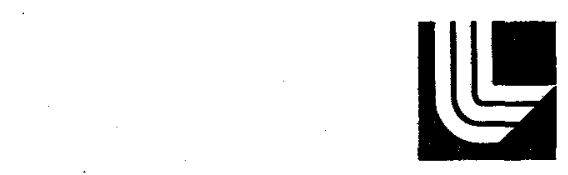

\section{LAWRENCE LIVERMORE LABORATORY}

University of Calfornia/Livermore, California/94550

\section{UCRI-52186 \\ FLOW-REGIME CHARACTERIZATION FOR HORIZONTAL TWO-PHASE STEAM FLOW

\author{
Clarence A. Calder
}

MS. date: October 5, 1976

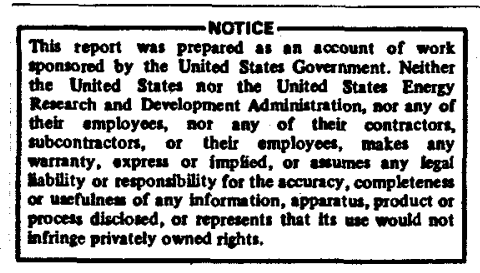




\title{
FLOW-REGIME CHARACTERIZATION FOR HORIZONTAL TWO-PHASE STEAM FLOW
}

\begin{abstract}
The reliable characterization of the flow reglme, given the fluid properties, flow rate, and piping configuration, would be a significant help in the design of instrumentation, energy-conversion machinery, and piping for two-phase geothermal flow. A relatively simple model, using Baker parameters, is described and applied to flow-regime data generated by high speed photography of two-phase steam flow. The experiments were conducted at the Geothermal Test Facility (GTF) at Lawrence Livermore Laboratory. Although results depend somewhat on the personal judgment and interpretation of the observer, the model was found to give a reasonable prediction of the flow regime for the flow ranges avallable at the GTF in 1- and 2-in.-diam pipes.
\end{abstract}

\section{Introduction}

The reliable prediction of flow regimes in horizontal two-phase flow is very difficult. However, some indication of the expected type of flow would be of considerable value in designing pipe dimensions for a desired flow condition. For example, a sampling probe in the flow should provide a reasonably good representative fluid sample for a homogeneous bubbly or droplet flow, but it would give unreliable information for a stratified or annular flow. Many models of varying complexity have been proposed and then compared to experimental data for a specific limited range of flow conditions. The technique usually incorporates a two-dimensional map with dimensioned or dimensionless parameters as coordinates, which may or may not be chosen on a rigorous theoretical or logical basis. The maps define regions or zones by transition lines separating the flow regimes. The transition lines are In fact broad bands because of the difficulty in classifying the flow near a transition.

The various published maps are not in good agreement. Apparently, this is largely due both to the lack of a standard definition of the possible flow 
regimes and to the experimenters' difficulty in describing the flow regime observed. Some methods are more general in that their extrapolation to flow conditions other than those used in their development is possible. Reference 1 gives a current description of many of the proposed flow-mapping techniques in use today.

One flow-mapping technique, developed by 0. Baker $^{2,3}$ in the early 1950 s for two-phase gas-11quid flow in the petroleum industry, will be described in detail as to its application in two-phase steam flow. This method is still widely used today for designing petroleum pipelines and is one of the simplest, most directly applicable mapping techniques. Predictions of the Baker method will be compared with experimental results from observation of 1-in.- and 2-in.-diam-pipe horizontal flow of low quality steam simulating a geothermal source. The data presented are photographs from high speed photography at several framing rates with image enhancement techniques employed to better define the flow-density distribution.

\section{Flow Regimes}

Flow patterns are defined by the possible characteristic configurations that the two phases may assume under the various flow and piping conditions of interest. There are no universally accepted definftions of flow regimes or flow patterns; some authors prefer to use a few basic patterns, while others use much more detailed regimes and subregimes that occur. Gravitational effects are evident in the horizontal flow patterns, with the liquid phase (tending to the lower leve1) producing an asymmetric distribution of the phases. To be consistent with the Baker charts, the flow regimes shown in Fig. 1 will be used. $^{3,4}$ The seven flow patterns or regimes are defined as follows:

- Bubbly flow

- Plug flow

Stratified flow
In bubbly flow, the liquid phase is continuous, with the gas phase distributed in small, discrete bubbles that tend to occur toward the upper part of the pipe.

Plug flow occurs when some gas bubbles approach dimensions of the order of the pipe diameter and are elongated in the axial direction. In this pattern, the gas and liquid phases are completely separated; the liquid phase is at the bottom of the pipe and the gas at the top. $-2-$ 


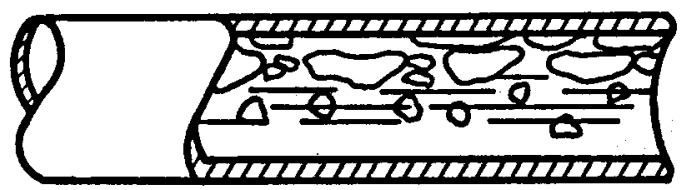

Bubble flow

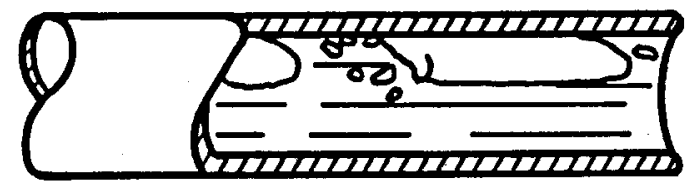

Plug flow

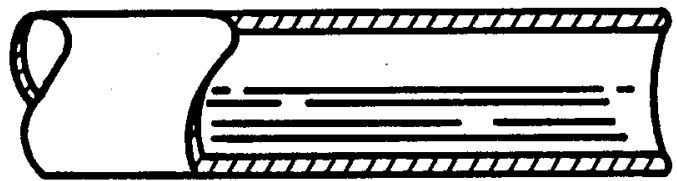

Stratified flow

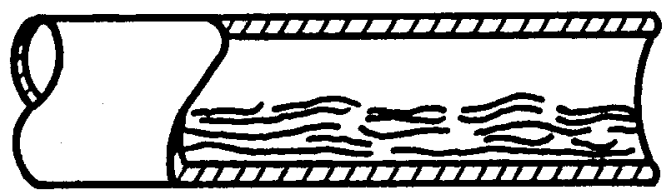

Wavy flow

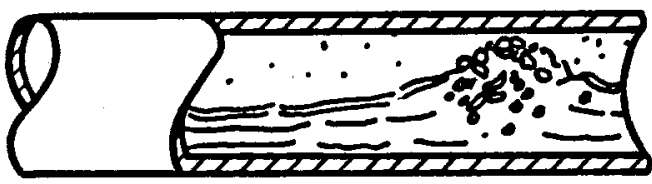

slug flow

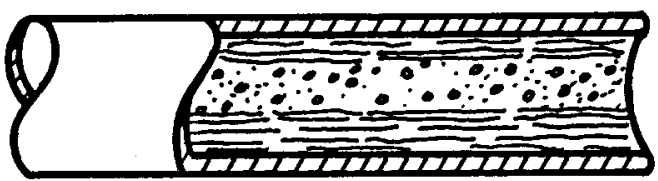

Annular flow

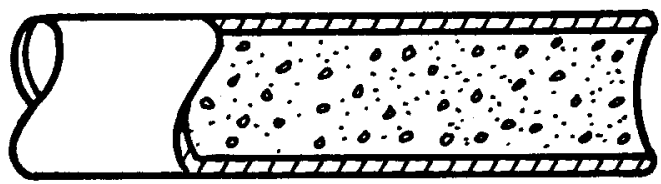

Dispersed (mist)

\section{Flow}

Fig. 1. Flow pattern in horizontal two-phase liquid-gas flow.

- Wavy flow

- Slug flow

- Annular flow

- Dispersed droplet flow
Wavy flow is an extension of stratified flow in which a larger gas velocity produces surface waves in the liquid.

This pattern is an extension of the wavy flow pattern in which the gas velocity is great enough to cause surface waves in the liquid to reach the top of the pipe. This produces flow segments that are completely liquid. This regime is defined by a liquid annulus (with an inner gas core) at the pipe wall; the annulus is thicker at the bottom of the pipe.

This pattern occurs when the gas phase is continuous with liquid droplets, dispersed throughout the flow (also called fog or mist flow). 


\section{Flow Regime Mapping}

Most flow-regime maps are developed empirically by plotting experimental observations of flow patterns on a graph with suitably chosen axes, although recent efforts have been directed toward defining the regime boundaries on a more rigorous theoretical basis. ${ }^{1}$ Then lines or bands are drawn to separate the possible regimes. The coordinates are usually related to the flow rates of the two phases or to flow rate and quality, and may be dimensioned or dimensionless quantities. For horizontal flow, one of the best known and still most widely used flow maps was developed by Baker in 1954. ${ }^{2,5}$ Although the Baker chart is not the most accurate of the currently used flow-regime mapping techniques, it has gained wide acceptance because of its relative simplicity and ease of application. The Baker chart for horizontal flow is a $\log -\log$ graph of two parameters called the Baker parameters, $B_{x}$ and $B_{y}$. which are defined as follows ${ }^{5}$ :

$$
\begin{aligned}
& B_{x}=531\left(\frac{W_{1}}{W_{v}}\right)\left(\frac{\rho_{v}^{0.5}}{\rho_{1}^{0.167}}\right)\left(\frac{\mu_{1}^{0.333}}{\sigma_{1}}\right) \\
& B_{y}=2.16 \frac{W_{v}}{A\left(\rho_{1} \rho_{v}\right)^{1 / 2}}
\end{aligned}
$$

The subscripts 1 and $v$ represent the liquid and gas phases, $W$ is mass flow rate in $1 \mathrm{~b} / \mathrm{hr}, \rho$ is density in $1 \mathrm{~b} / \mathrm{ft}^{3}, \mu$ is viscosity in centipoise, $\sigma$ is the surface tension in dynes/cm, and $A$ is the pipe cross-sectional area in $\mathrm{ft}^{2}$. If $\mathrm{X}=\mathrm{W}_{\mathrm{v}} /\left(\mathrm{W}_{\mathrm{v}}+\mathrm{W}_{1}\right)$ is the quality and $\mathrm{Q}=\mathrm{W}_{\mathrm{v}}+\mathrm{W}_{1}$ the total flow rate for the two-phase flow, Eqs. 1 and 2 can be more conveniently written for the present application as

$$
\begin{aligned}
& B_{x}=531\left(\frac{1-X}{X}\right)\left(\frac{\rho_{v}^{0.5}}{\rho_{1}^{0.167}}\right)\left(\frac{\mu_{1}^{0.333}}{\sigma_{1}}\right) \\
& B_{y}=2.16 \frac{Q X}{A\left(\rho_{1} \rho_{v}\right)^{1 / 2}}
\end{aligned}
$$

The Baker chart is shown in Fig. 2. The two-phase flow has been assumed isothermal, turbulent in both the liquid and vapor phases, and steady (in 


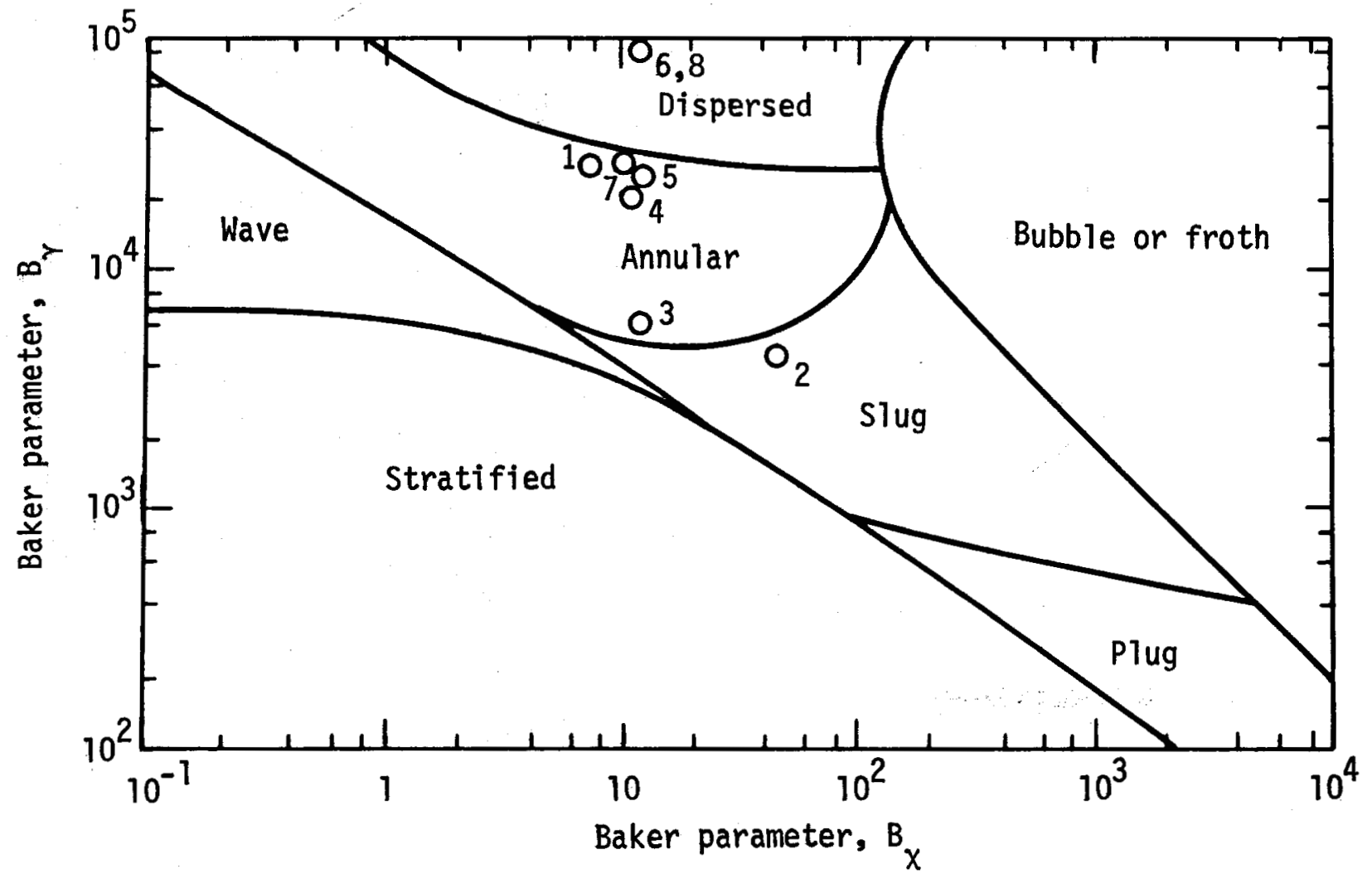

Fig. 2. Baker chart for flow-regime prediction. (Indicated data points are flow conditions for tests reported.)

that there is no slip); pressure loss is assumed insignificant. To apply the Baker chart, the viscosity and surface tension of water as a function of temperature are required. Plots of these quantities are shown in Figs. 3 and 4 , where the data for the temperature range from 300 to $500^{\circ} \mathrm{F}$ has been extracted from plots over an extended temperature range given in Ref. 6 .

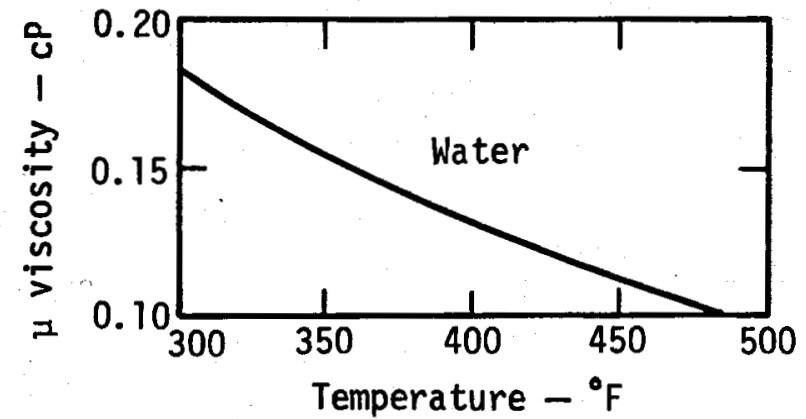

Fig. 3. Dynamic viscosity vs temperature for water at $300-500^{\circ} \mathrm{F}$.

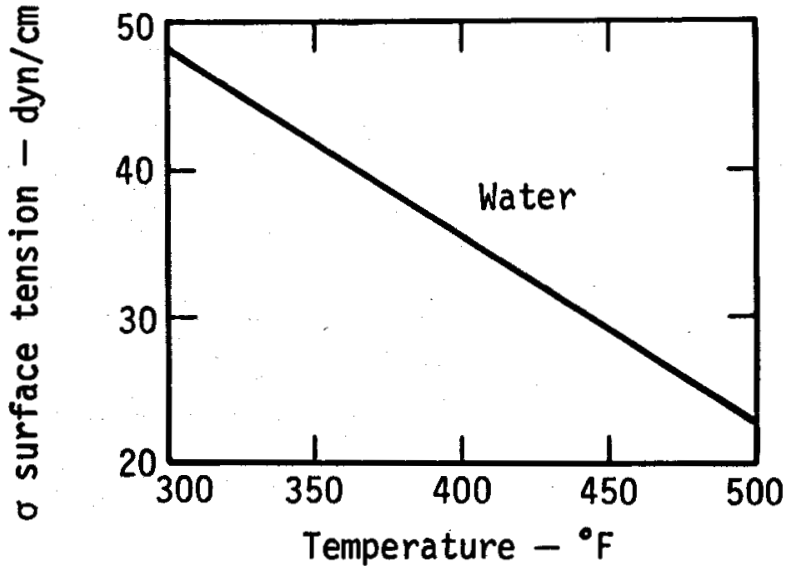

Fig. 4. Surface tension vs temperature for water at $300-500^{\circ} \mathrm{F}$. 


\section{Flow-Visualization Experiments}

The Geothermal Test Facility (GTF) was employed to provide a steam source for flow-visualization experiments. The facility was constructed to support development of the geothermal total flow concept ${ }^{8}$ and has been described in detail. 7 Basically, it is a hot-water generator from which the pressurized water is flashed to a desired two-phase pressure (or temperature) low quality condition for test purposes. The quality of the mixture is controlled by the selection of the pressurized water temperature where a constant enthalpy expansion to the two-phase fluid state is assumed. Maximum conditions for the hot-water generator are $550^{\circ} \mathrm{F}$ and $1000 \mathrm{psia}$ with 1 ong term flow rates of about $2.5 \mathrm{lb} / \mathrm{s}$ possible.

The flow rate to the test spool is accurately determined by using an orifice-meter measurement taken before flashing the pressurized water. Temperature and pressure of the water are also recorded using conventional strain-gage pressure transducers and thermocouples. Temperature of the flashed two-phase steam is measured at the inlet and outlet of the test spool by using thermocouples intrinsically mounted on the outer wall surface of the stainless-steel pipe with a layer of insulation over the thermocouple. Pressure, although dependent on the two-phase temperature, was also recorded as a check near the inlet and outlet of the spool by using pressure taps on the top of the pipe. All data are recorded on a Kaye digital data-acquisition system. The thermocouple temperatures are given directly in degrees centigrade, but the pressure output in volts must be converted to psia by using the appropriate sensitivity factor. The 50-in.-spool section is designed to permit the testing of a variety of possible two-phase instrumentation techniques; flow visualization is one. 9

The two-phase thermodynamic state properties in the spool test-section are evaluated with the use of an interactive computer program called "SPOOL." This program uses a large set of subroutines for the calculation of steam properties based on an internationally agreed-upon set of equations called the "1967 IFC Formulation for Industrial Use". 10 The program assumes a constant enthalpy expansion from the compressed water state to the two-phase steam state, and requires an input of the measurements of the water pressure and temperature, the orifice-meter zero flow and the test-flow delta pressure, and the test-spool temperature and pressure. The output provides the two-phase conditions of enthalpy, flow rate, quality, specific volume, and 
average flow velocity, as well as repeating the measured spool temperature and comparing the corresponding saturated pressure with the measured pressure.

Flow-visualization experiments were conducted using transparent glass sections of both $1-$ and 2-in. i.d. sandwiched between Schedule 80304 stainless-steel pipe of the same corresponding diameter. Figure 5 shows the test-spool section with the 1-in. glass section, 24 in. 1ong, in place.

In all cases, the glass section was lighted from the back and top; a teflon sheet served as a diffuser. A high speed 16-mm camera, either a Hycam or a Milliken, was positioned as shown; high speed Ektachrome film, EF type 7242 , was used in all runs. A mirror below the glass pipe was positioned in some runs to give a bottom view of the flow, while in other cases it was simply angled to reflect the top floodlight for bottom lighting and for a more unfform light intensity.

A closeup view of the 5-1n.-1ong, 2.0-in. 1.d. by 2.7-in. o.d. glass spacer pipe appears in Fig. 6. The spacer pipe was held in place by the Invar tie rods shown. The angle iron used for alignment and stiffening minimized the bending moment carried by the glass section. A similar arrangement is shown in Fig. 7 for the 24-in.-long, 1.0-in. 1.d. by 1.3-in. 0.d. glass process pipe. This pipe has conical ends for mounting to the flange, so tie rods were not necessary. The digital indicator was used to provide a run number on the film. The indicator, flood lights, and high speed motion camera were remotely actuated so that a test series could be conducted without personnel in the area when the glass section was pressurized. Both glasssection designs were tested at operating temperature and three times operating pressure before their use in the experiments.

In addition to the black-and-white photographs taken from selected frames of the $16 \mathrm{~mm} f i l m$, the data was also analyzed with the use of two imageIntensification schemes. The first produces a three-dimensional photograph from the negative or photograph in which the third dimension is proportional to the density of the film data at any particular location on the film. The second method is simflar, but various colors represent certain film density ranges. In most cases, flow patterns were found to be more easily defined using these methods over the conventional photograph. An example of the Image intensification result is demonstrated in Fig. 8 for 2-in. pipe flow with the average quality and velocity of $18.2 \%$ and $18.7 \mathrm{ft} / \mathrm{s}$, respectively. The black-and-white photograph, three-dimensional image intensification, and color image intensification can be compared for the same 16-mm frame. The 


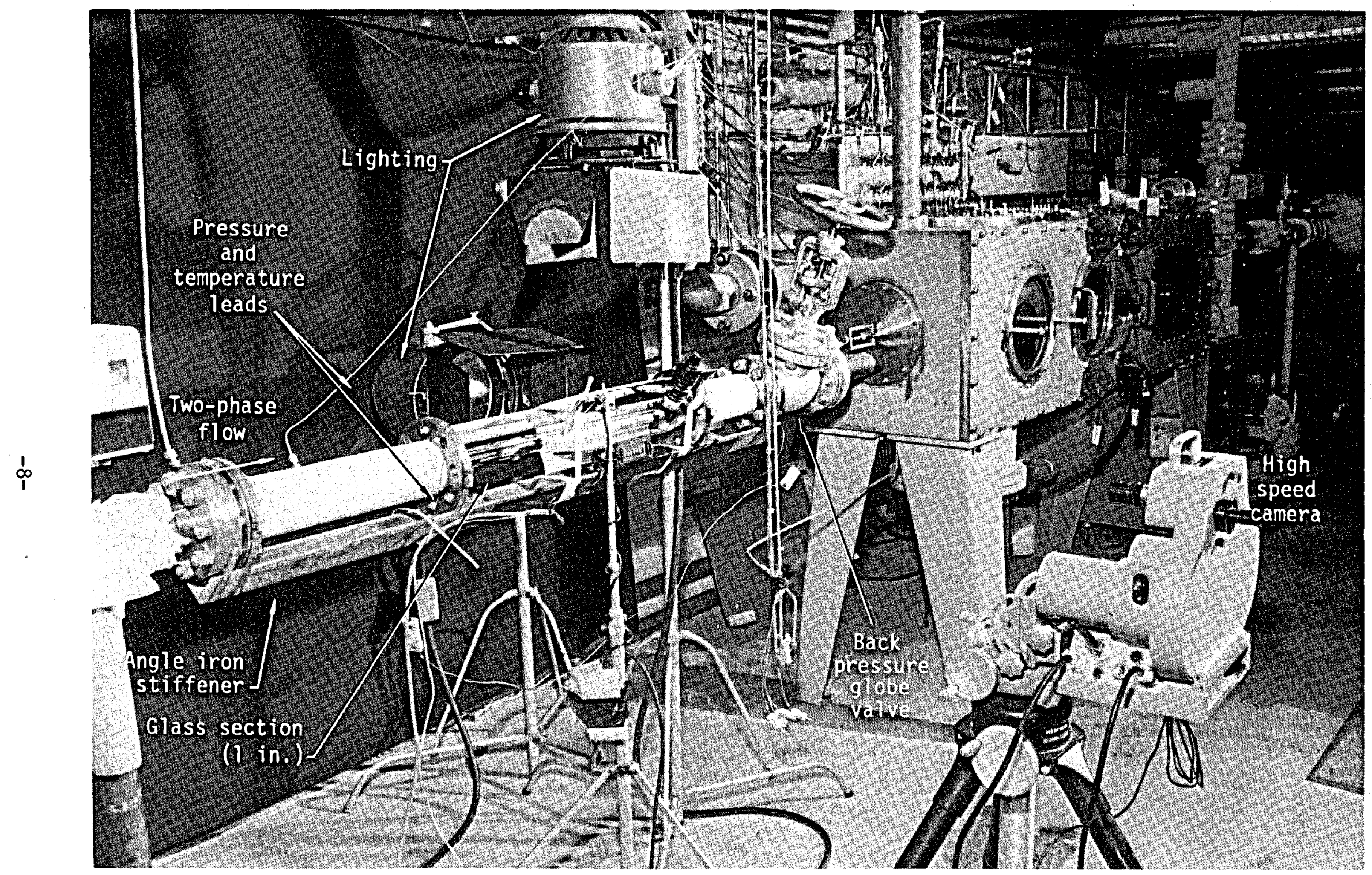

Fig. 5. Two-phase instrumentation-development test spool showing 1-in.-diam glass section for flow visualization. 


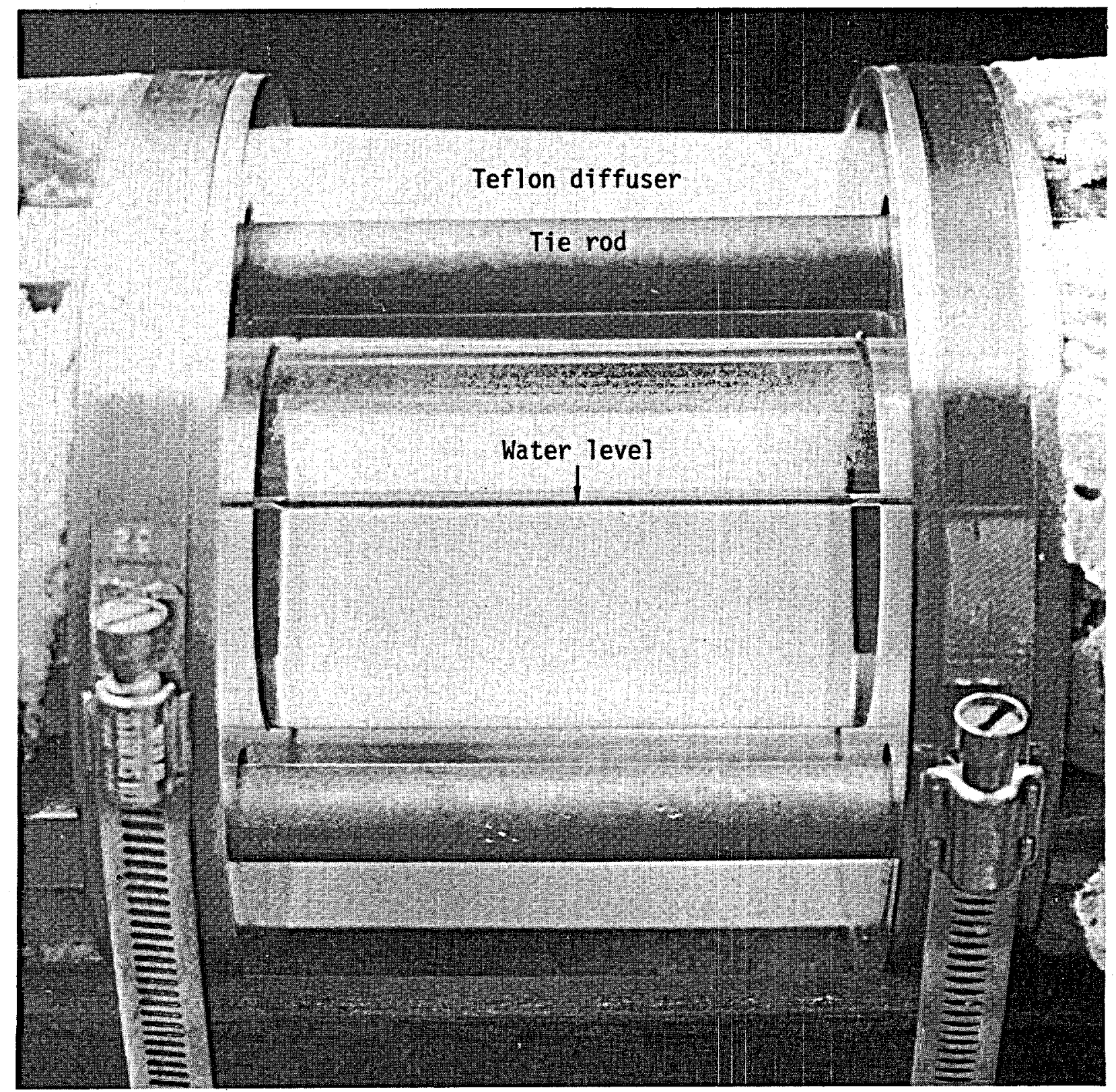

Fig. 6. Glass spacer pipe (2-in.-diam) for flow visualization. (Pipe was about two-thirds full of water at time of photograph.)

numbers on the color chart in Fig. 8c give the relative density ranges for each color band, black being the most dense. The field of view of the blackand-white photograph is slightly shortened on the right side. 


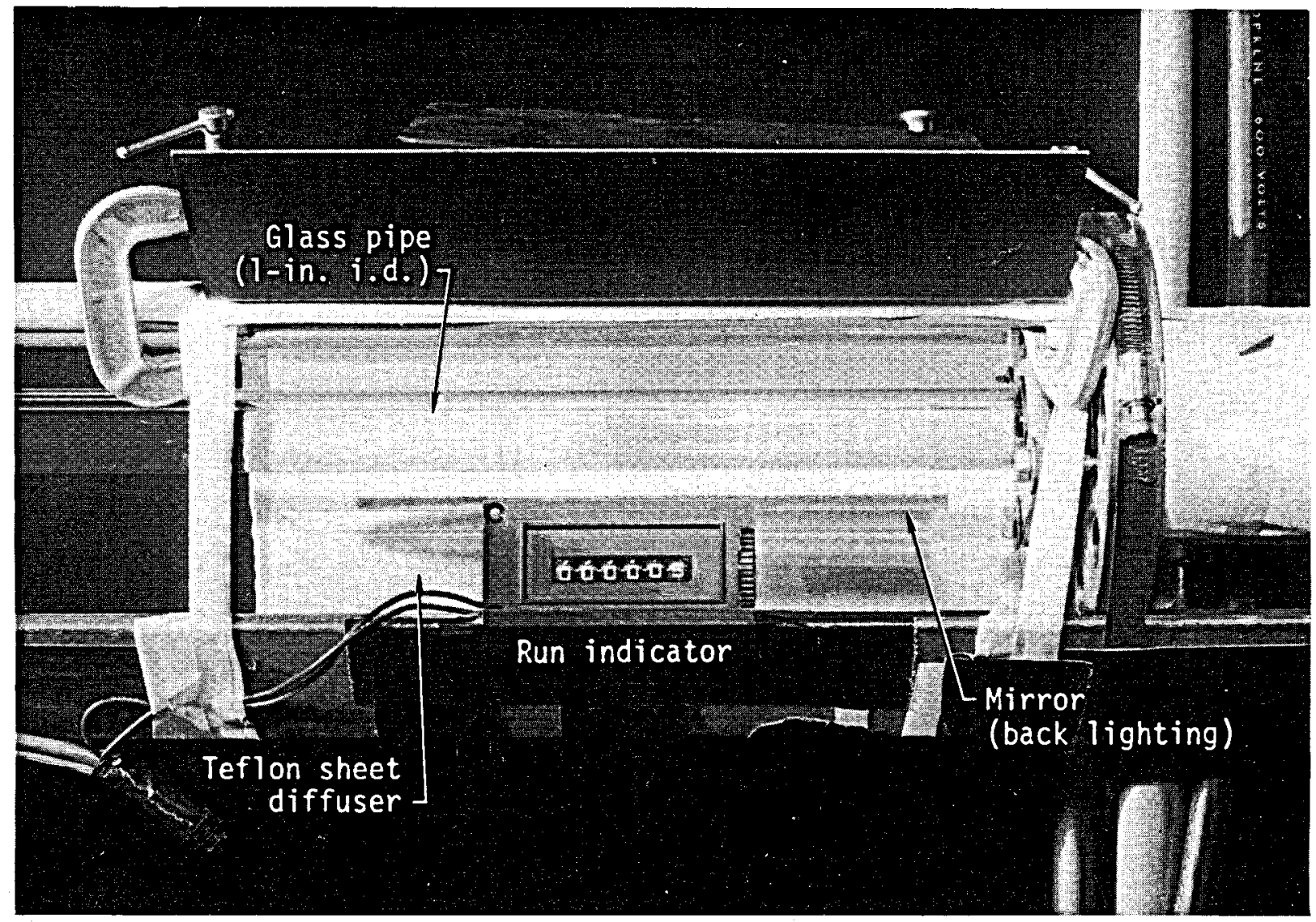

Fig. 7. Glass process pipe (1-in.-diam) for flow visualization.

\section{Results}

Table 1 gives a summary of the 1-in.- and 2-in.-diam tests for which flow-visualization data are to be presented. The location on the Baker chart for the flow condition of each run is shown in Fig. 2. With the exception of runs 1 and 2, all data are for approximate field conditions of 200 psia, $18 \%$ quality, and varying flow rates. The data for the 2-in.-diam pipe were taken before the installation of a higher capacity pump, so that maximum flow rate on a continuous basis was about $1.6 \mathrm{lb} / \mathrm{s}$. The new pump should permit testing in 2-in. spools at over $2.0 \mathrm{lb} / \mathrm{s}$. The 1-in.-diam pipe runs were taken with the high capacity pump installed, but the flow choked at about $1.8 \mathrm{1b} / \mathrm{s}$. 


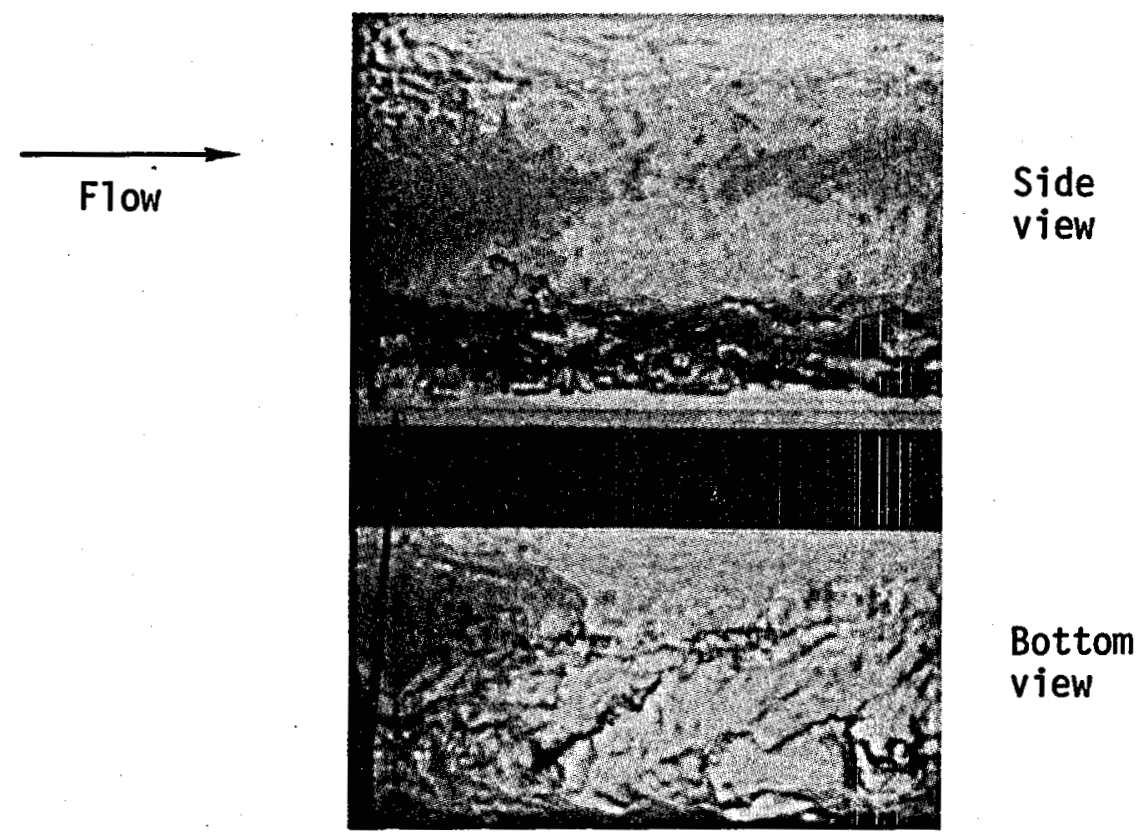

(a)

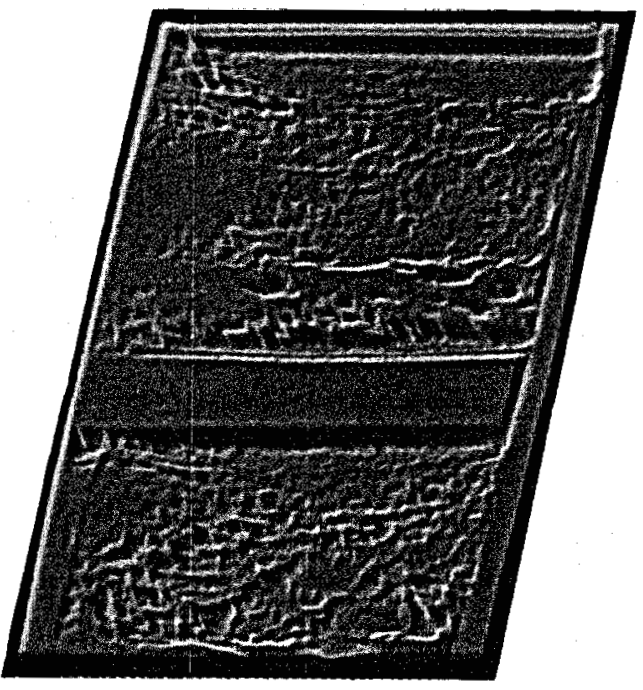

(b)
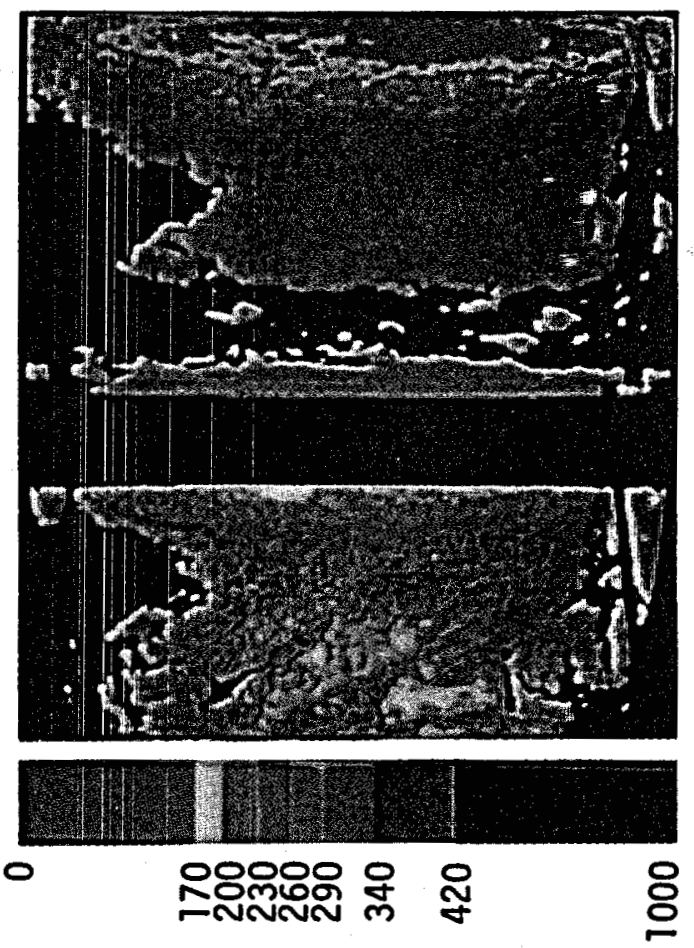

Relative density range

(c)

Fig. 8. Two-phase flow visualization. Comparison of a regular photograph with three-dimensional and color image-intensification results taken from the same 16-m frame. Flow was $18.2 \%$ quality at average velocity of $18.7 \mathrm{ft} / \mathrm{s}$ In the 2-in.-diam pipe. (a) black-and-white photograph; (b) three-dimensional image intensification; (c) color image intensification. 
Table 1. Summary of flow-visualization data.

\begin{tabular}{|c|c|c|c|c|c|c|c|}
\hline $\begin{array}{c}\text { Framing } \\
\text { rate/shutter } \\
\text { speed }\end{array}$ & Run & $\begin{array}{c}\text { Pipe } \\
\text { diameter } \\
\text { (in.) }\end{array}$ & $\begin{array}{l}\text { Temp. } \\
\left({ }^{\circ} \mathrm{F}\right)\end{array}$ & $\mathrm{P}_{\text {(psiat }}$ & $\begin{array}{c}\text { Flow rate } \\
(1 \mathrm{~b} / \mathrm{s})\end{array}$ & $\begin{array}{l}\text { Quality } \\
(\%)\end{array}$ & $\begin{array}{l}\text { Average } \\
\text { velocity } \\
(f t / s)\end{array}$ \\
\hline $1000 / \frac{1}{2500}$ & 1 & $2^{a}$ & 334 & 109 & 1.59 & 18.7 & 60.4 \\
\hline $1000 / \frac{1}{2500}$ & 2 & $2^{b}$ & 434 & 361 & 1.11 & 7.6 & 6.3 \\
\hline $100 / \frac{1}{4000}$ & 3 & $2^{b}$ & 389 & 218 & 0.48 & 17.9 & 9.2 \\
\hline $100 / \frac{1}{4000}$ & 4 & $2^{b}$ & 389 & 218 & 1.51 & 18.5 & 30.0 \\
\hline $250 / \frac{1}{12,000}$ & 5 & $1^{b}$ & 388 & 215 & 0.51 & 18.0 & 39.5 \\
\hline $250 / \frac{1}{12,000}$ & 6 & $1^{b}$ & 386 & 210 & 1.55 & 18.7 & 129 \\
\hline $1000 / \frac{1}{2500}$ & 7 & $1^{a}$ & 379 & 193 & 0.53 & 18.0 & 42.7 \\
\hline $3000 / \frac{1}{7500}$ & 8 & $1^{a}$ & 382 & 201 & 1.78 & 18.5 & 143 \\
\hline
\end{tabular}

aside view only.

${ }^{\mathrm{b}}$ Side and bottom view.

Flow-visualization results for the 2-in. flow appear in Figs. 9-12 and for 1-in. flow in Figs. 13-16. The 2-in. runs include the image enhancement results for three dimensional and color image intensification and give a direct comparison with the conventional flow photograph. As with Fig. 8, the black-and-white photograph on Figs. 9, 10, and 12 has a shorted field of view on the right side. Although image enhancement was done for the runs, these results are not included since they did not significantly improve the interpretation from the photograph. Flow velocities were sufficiently high in the 1-in. cases to give well-mixed flow and small density variations. The predicted flow state is indicated in each case on an expanded section of the Baker chart. 


$$
\begin{gathered}
\text { Run } 1 \\
P=109 \text { psia } \\
Q=1.59 \mathrm{lb} / \mathrm{s} \\
X=18.7 \% \\
V_{\text {ave }}=60.4 \mathrm{ft} / \mathrm{s}
\end{gathered}
$$
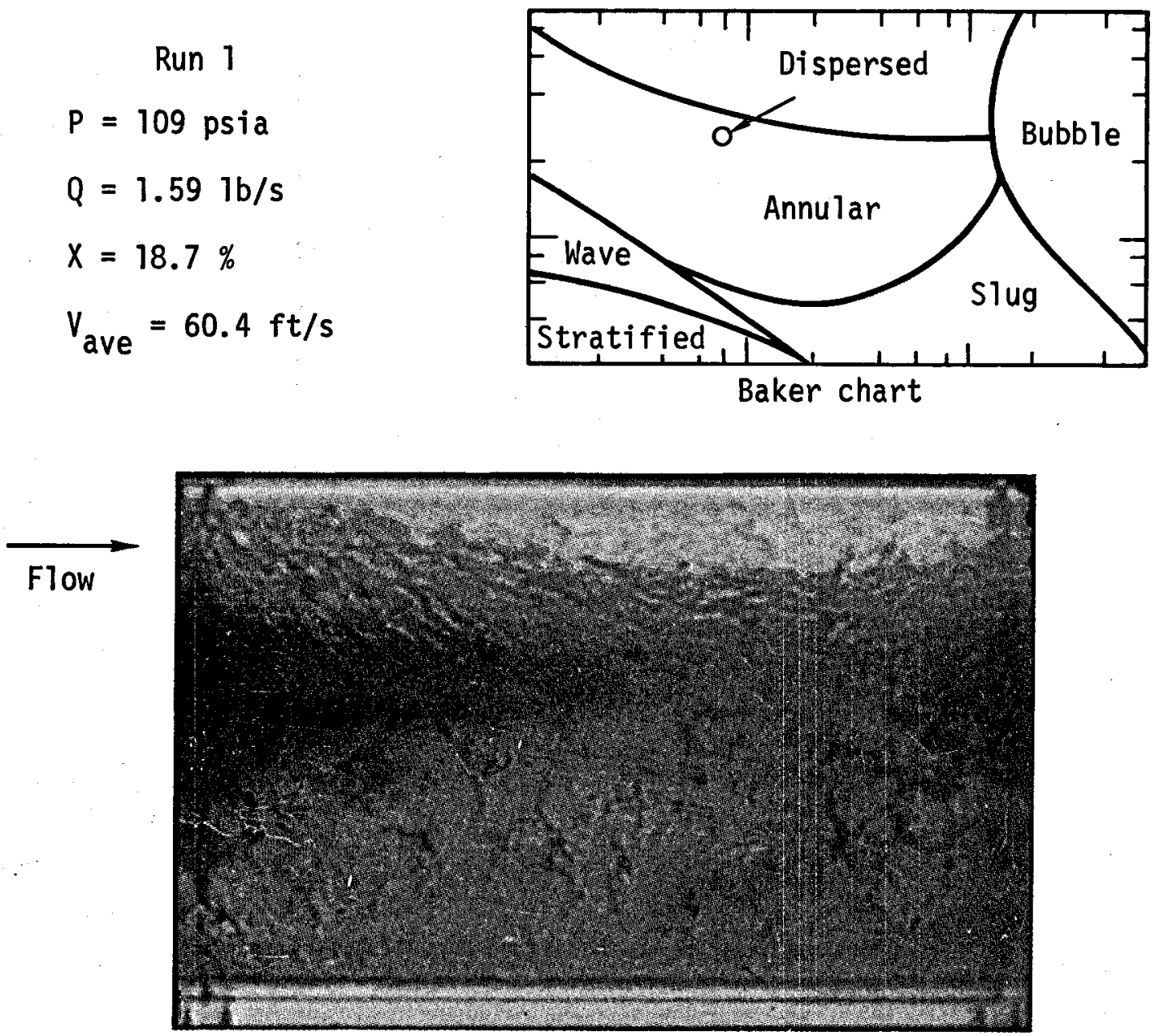

(a)

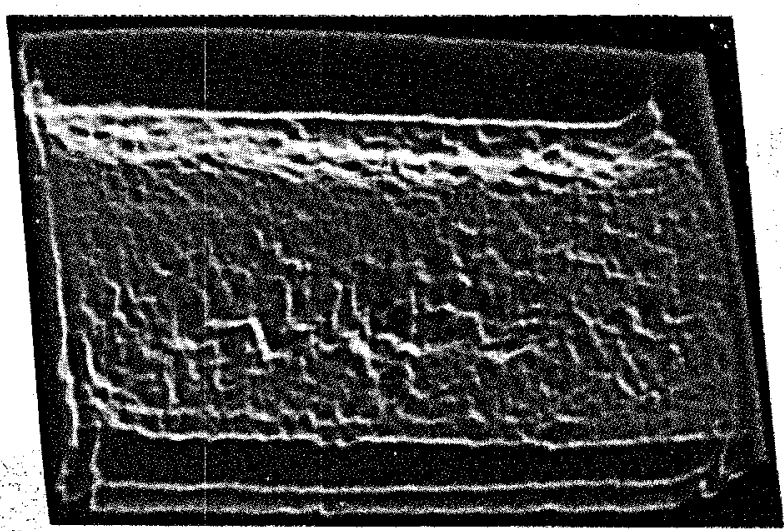

(b)

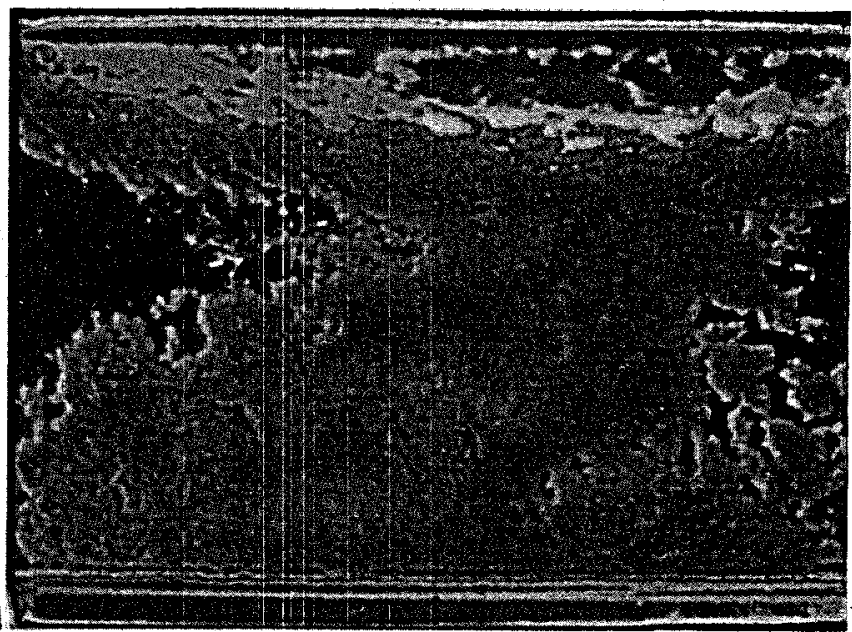

(c)

F1g. 9. Flow visualization (2-in. pipe), run 1. (a) photograph of typical frame, side view; (b) three-dimensional enhancement; (c) color enhancement. 


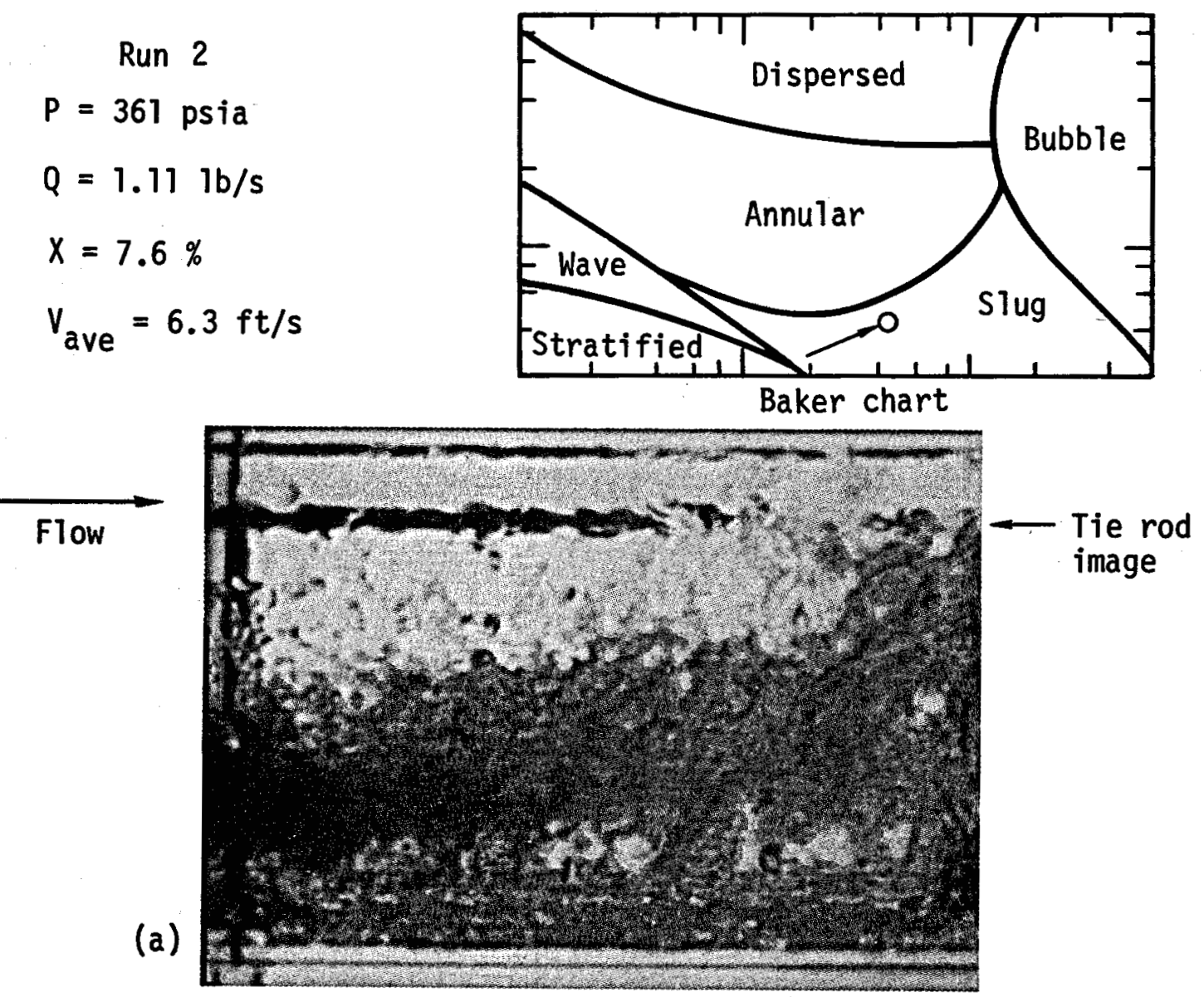

(c)
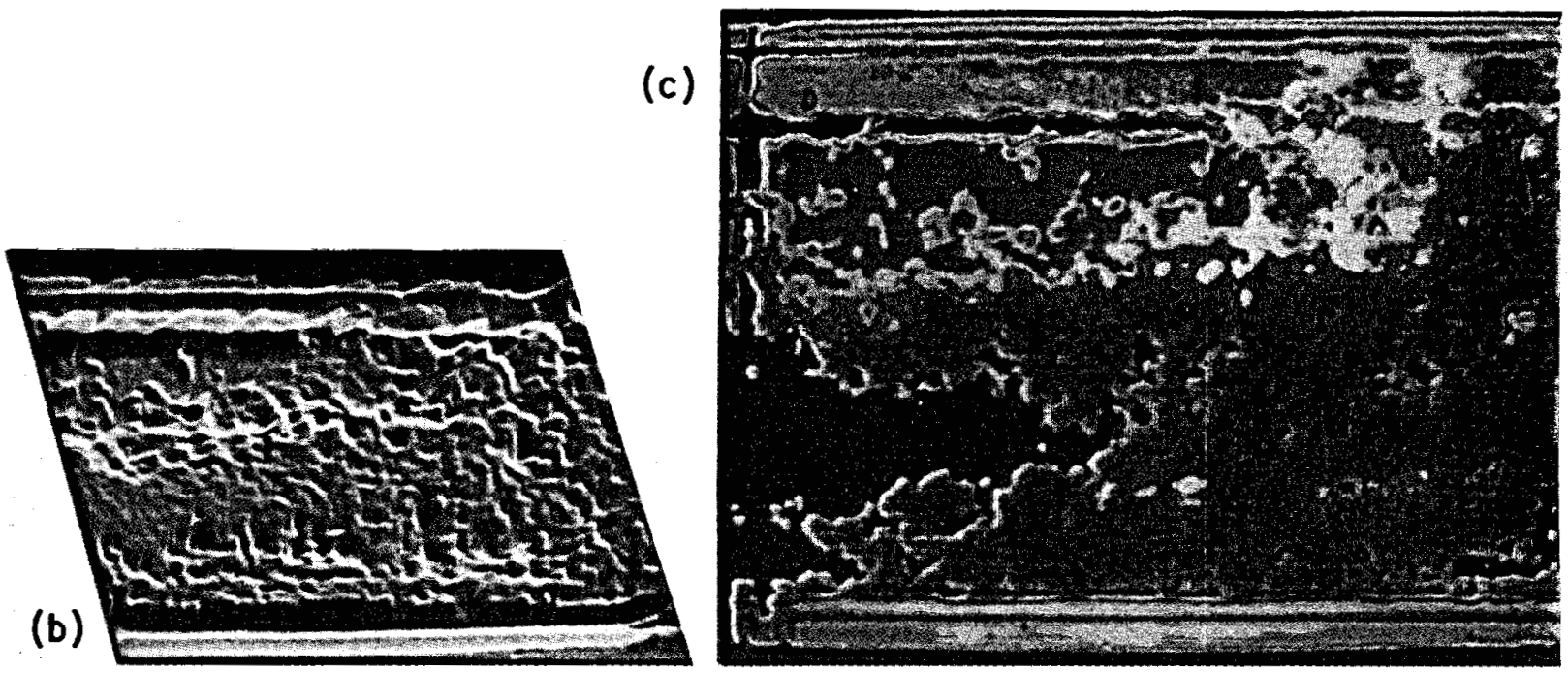

F1g. 10. Flow visualization (2-in. pipe), run 2. (a) photograph of typical frame, side view; (b) three-dimensional enhancement; (c) color enhancement. 
Run 3

$P=218$ psia

$Q=0.48 \mathrm{lb} / \mathrm{s}$

$X=17.9 \%$

$v_{\text {ave }}=9.2 \mathrm{ft} / \mathrm{s}$
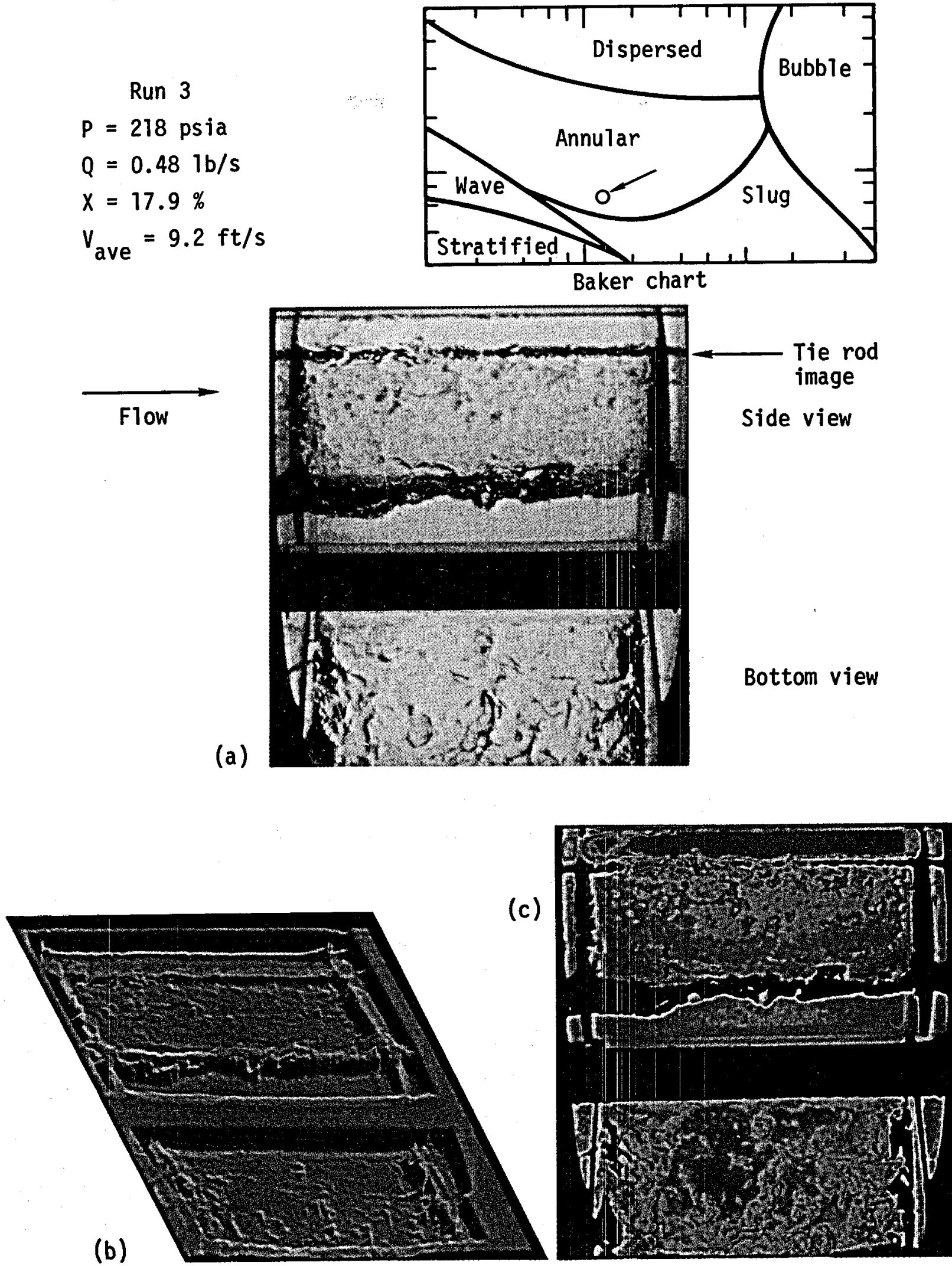

Fig. 11. Flow visualization (2-in. pipe), run 3. (a) photograph of typical frame; (b) three-dimensional enhancement; (c) color enhancement. 


$$
\begin{gathered}
\text { Run } 4 \\
P=218 \mathrm{psia} \\
Q=1.51 \mathrm{1b} / \mathrm{s} \\
X=18.5 \% \\
V_{\text {ave }}=30.0 \mathrm{ft} / \mathrm{s}
\end{gathered}
$$
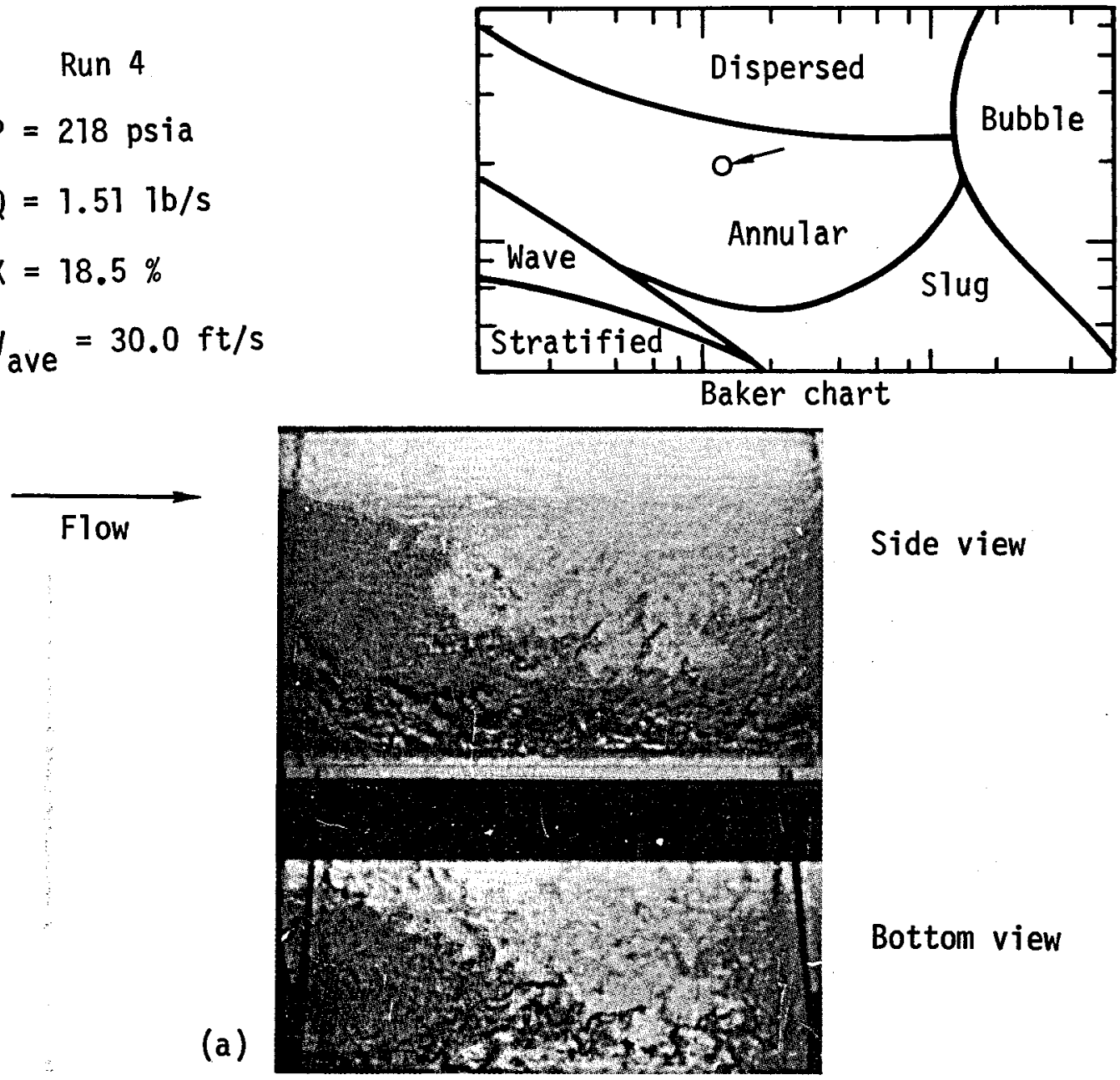

Side view

(a)

(c)

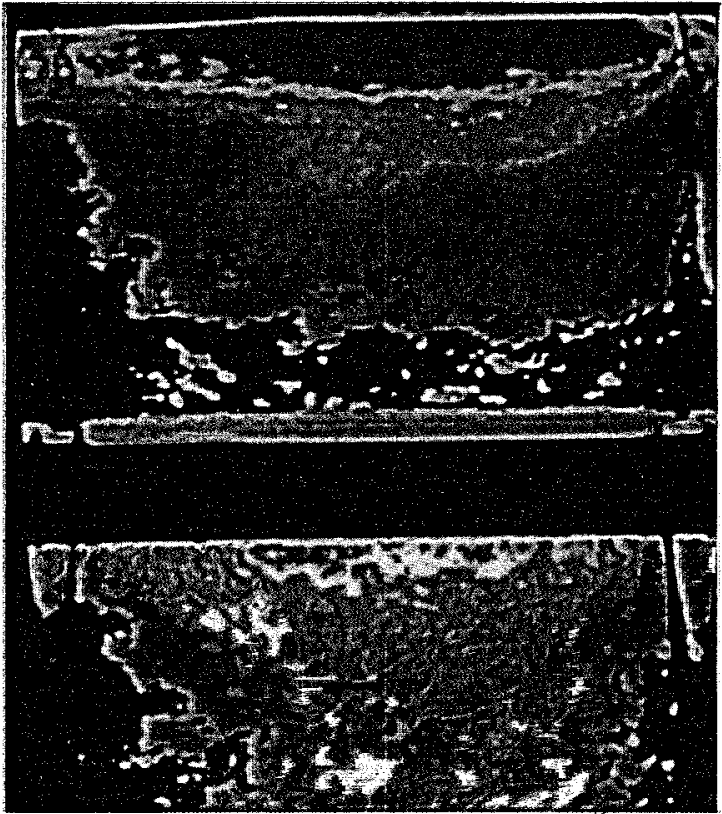

(b)

Fig. 12. Flow visualization (2-in. pipe), run 4. (a) photograph of typical frame; (b) three-dimensional enhancement; (c) color enhancement. 


$$
\begin{gathered}
\text { Run } 5 \\
P=215 \mathrm{psia} \\
Q=0.51 \mathrm{lb} / \mathrm{s} \\
X=18.0 \% \\
V_{\text {ave }}=39.5 \mathrm{ft} / \mathrm{s}
\end{gathered}
$$
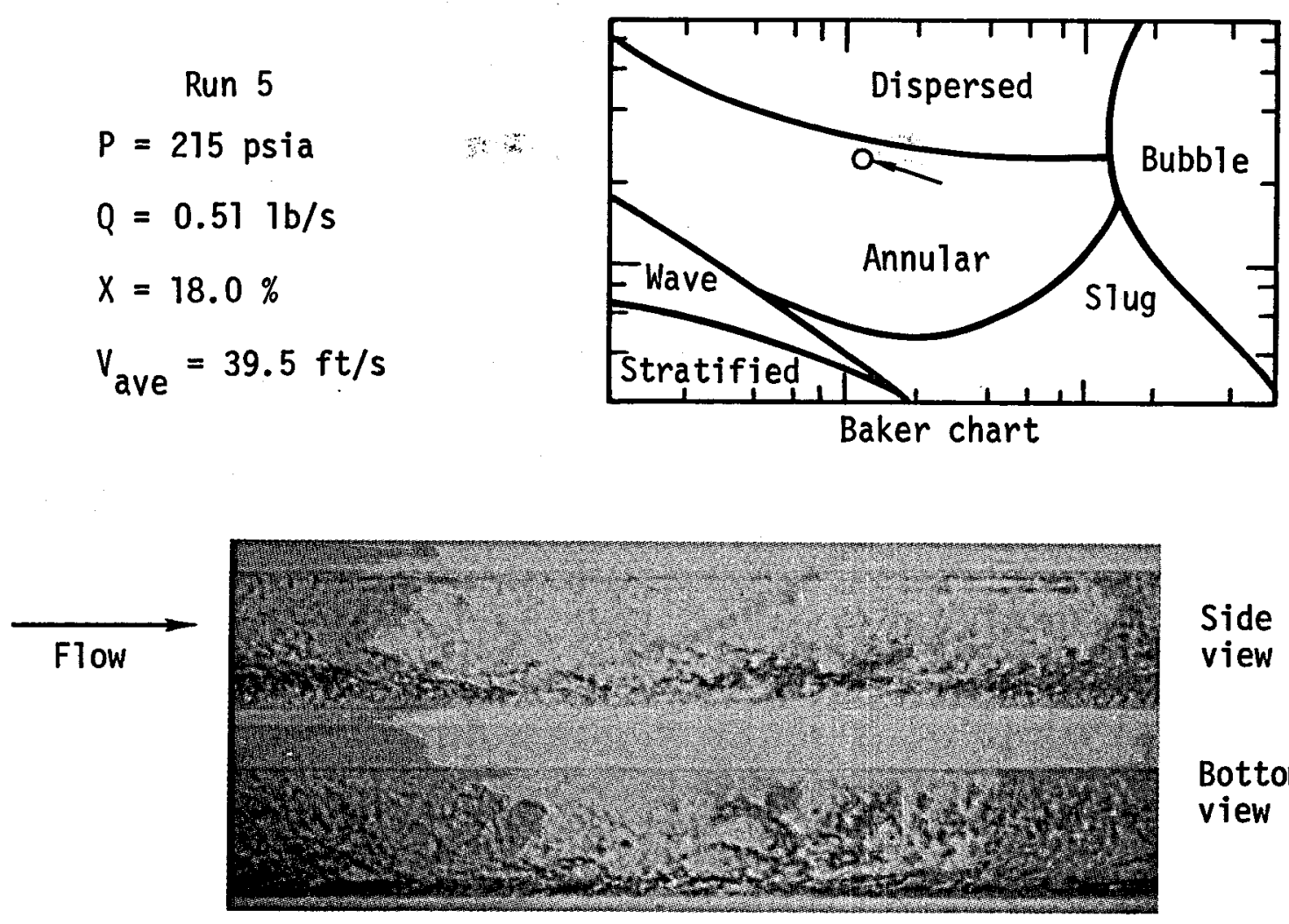

Side

view

Bottom

view

Photograph of typical frame

Fig. 13. Flow visualization (1-in. pipe), run 5. 
Run 6

$P=210$ psia

$Q=1.55 \mathrm{lb} / \mathrm{s}$

$X=18.7 \%$

$V_{\text {ave }}=129.0 \mathrm{ft} / \mathrm{s}$
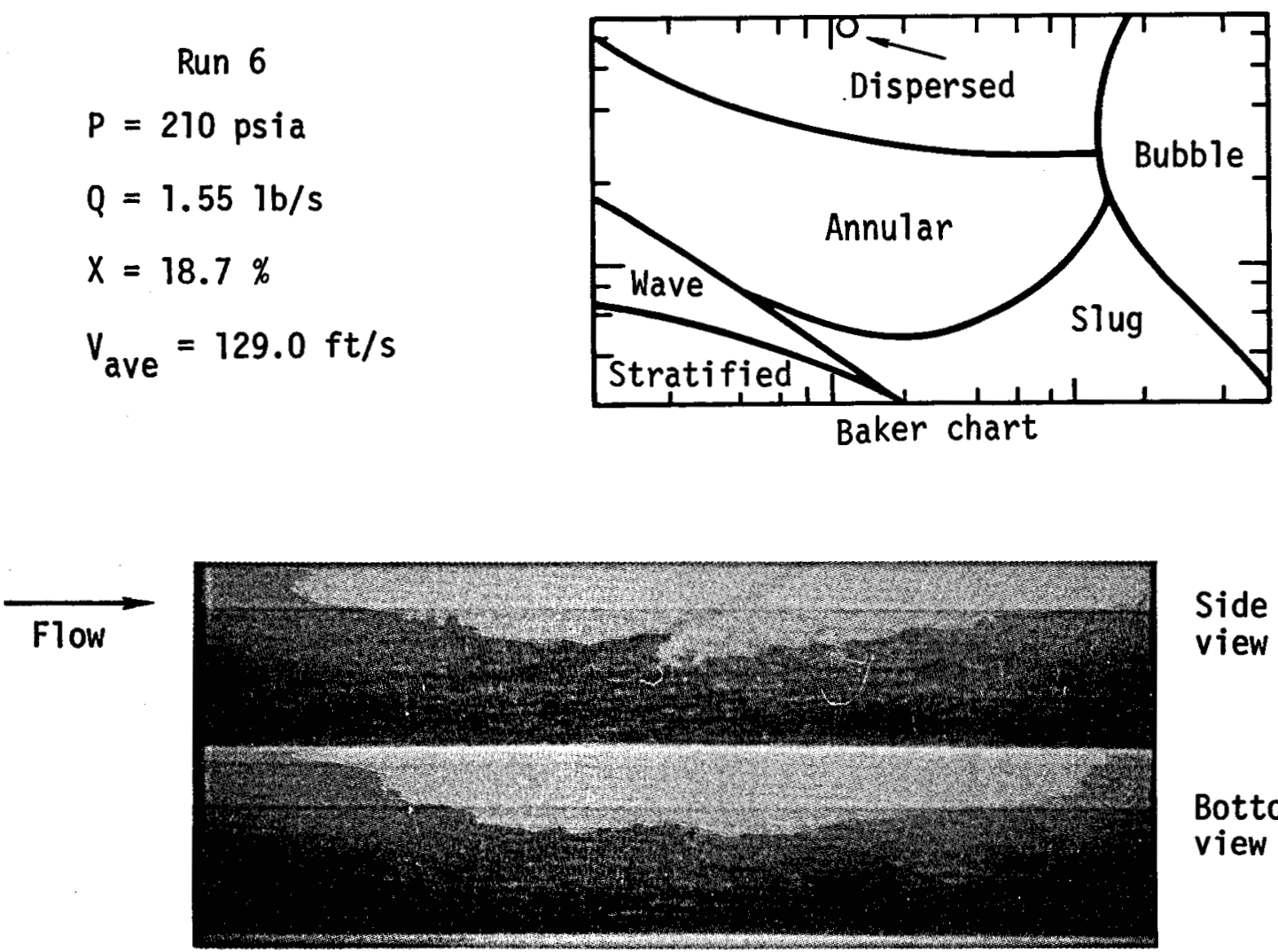

Side

view

Photograph of typical frame

F1g. 14. Flow visualization (1-in. pipe), run 6. 


$$
\begin{gathered}
\text { Run } 7 \\
P=193 \mathrm{psia} \\
Q=0.53 \mathrm{lb} / \mathrm{s} \\
X=18.0 \% \\
V_{\text {ave }}=42.7 \mathrm{ft} / \mathrm{s}
\end{gathered}
$$
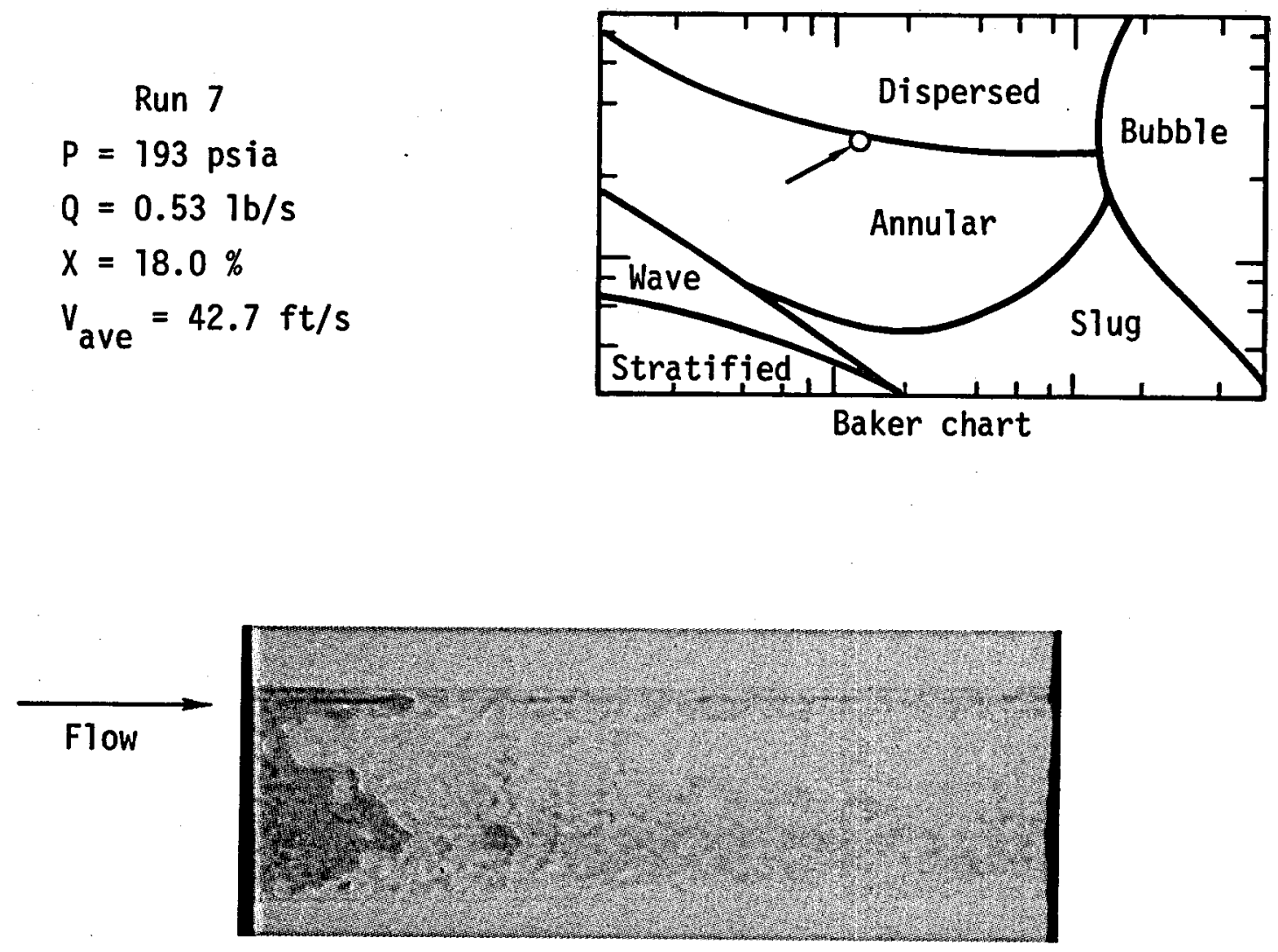

Photograph of typical frame - side view

Fig. 15. Flow visualization (1-in. pipe), run 7. 

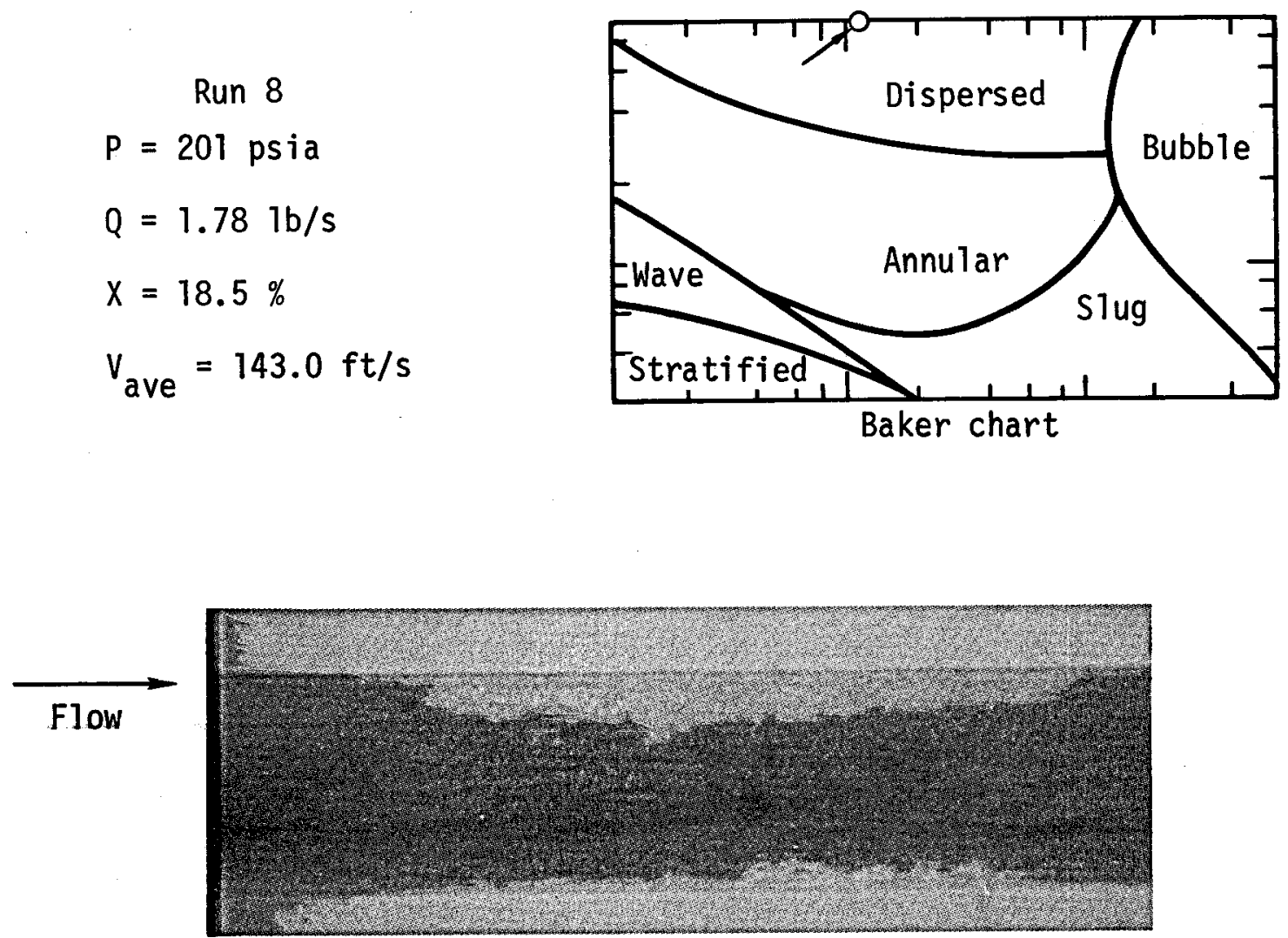

Photograph of typical frame - side view

Fig. 16. Filow visualization (1-in. pipe), run 8 . 


\section{Discussion}

Typical field two-phase conditions at flow rates obtainable in the GTF lead to flow regimes concentrated in the annular region of the Baker chart for 2-in. pipe flow. The upper annular and dispersed regions were obtained for 1-in. pipe flow. Although absolute flow patterns were not easily interpreted from the 16-mm film or the corresponding single frame photographs, the general flow nature was approximately defined by the Baker chart prediction. In all cases, some liquid flow at the inner wall boundary was noted, with a greater concentration of liquid flow near the pipe bottom. Some runs actually showed reverse flow for the outer liquid annulus, while others indicated a churning or screw motion of the fluid. In no case was the flow considered ideally dispersed or in a state that would be called uniformly fog or mist flow.

Figures 9 and 10 show side views of flow predicted by the Baker chart to be in the annular regime but tending towards dispersed flow. This is a reasonable description of the flow pattern found, with liquid flow near the wall evident in both cases. The flow density is noted to be greater near the bottom of the pipe, as expected, but this may be misleading because of the lighting configuration. These runs used a reflecting mirror at the underside of the pipe to achieve nearly uniform lighting, but this arrangement still tends toward higher lighting intensity near the top of the pipe. Thus, the greater flow density indicated near the lower part of the pipe may be somewhat influenced by the lighting technique. The flow is sufficiently transparent in run 2, Fig. 10, for the image of a tie rod to be clearly evident. As a general rule, the flow was noted to be clearer at the lower flow rates and lower flow quality. As would be expected, run 2 shows the greatest density variation, being transparent at the top and highly opaque near the bottom.

Runs 3 and 4 in Figs. 11 and 12 show field-condition runs at moderatly low and moderately high flow rates that show up as an annular flow regime on the Baker chart. These runs had the mirror on the underside of the transparent pipe section angled to provide a simultaneous bottom view of the flow. This arrangement results in a slightly brighter image at the top portion of the side and bottom views; this must be considered when analyzing density variations in the flow field. The lower flow-rate condition of run 3 leads 
to a more transparent flow, and the tie-rod image from the curved glass section is clearly evident. The flow in run 3 appears to be a combination of stratified and annular, as there is a definite layer of liquid in the lower portion of the pipe. The higher flow rate of run 4 leads to a more uniform flow distribution, as predicted by the Baker chart.

The corresponding three-dimensional and color enhancement photographs in Figs. 9-12 provide a clear representation of the density variations in the flow; the liquid concentrations nearer the bottom of the pipe are evident in all runs. These techniques, of course, are likewise influenced by the slightly uneven lighting used for the flow photography. They also indicate a brighter lighting area (hot spot) near the center of the flow because the flood lamp intensity was not evenly distributed.

Similar flow-visualization data for the 1-in. spool is shown in Figs. 13-16. In these cases, much higher velocities are obtained for the same flow rate when compared with the 2-in.-spool flow; these higher velocities result in a more evenly distributed flow pattern. The flow regime indicated by the Baker chart for runs 5 and 7 in Figs. 13 and 15 is annular, but very close to the annular-dispersed flow-regime border. Runs 6 and 8 in Figs. 14 and 16 lie well within the dispersed flow regime predicted by the Baker chart. Both side and bottom views were taken with runs 5 and 6 , but only side views with runs 7 and 8 as shown. The same comments on 1ighting-intensity distribution apply for the 1-in. flow; the central hot spot is even more evident. The two runs at the lower velocities show liquid flow at the wall in an annular flow fashion predicted by the Baker chart. The high velocity flow conditions are much more dispersed, as expected.

\section{Conclusions}

Flow visualization provides an excellent method of evaluating the flow regimes present for various flow conditions. The information is especially useful in designing instrumentation and sampling techniques that may be highly influenced by the distribution of the flow. Knowing the flow regime for given conditions should also be invaluable in the design of nozzles and energy-conversion machinery. The Baker chart, based on the limited flow conditions used in this study, appears to give a reasonable prediction of 
the flow pattern or regime expected for any given flow conditions. It is also a relatively simple method to apply.

In preparation for possible future flow-visualization studies in the laboratory and especially in the field with actual geothermal flow, several recommendations are made as a result of this work:

- The Baker chart provides a reasonable quick-1ook method of predicting the flow regime for given conditions.

- The use of color film, at least with clean water, does not appear to have any advantages over black-and-white film.

- Recorded flow densities are influenced by the lighting method and hot spots in the flood lamps. This would be reduced by shadowgraph (back lighting only) and by locating the flood lamp farther from the transparent section. Higher speed black-and-white film could be used to account for the decreased lighting intensity.

- Three-dimensional color image-enhancement techniques provide a useful addition to conventional photography for the evaluation of flow patterns and flow-density variations.

- Glass process pipe has a sufficient factor of safety for use at conditions considerably above rated operating pressure and temperature. Beaded glass pipe is recommended for future work, since alignment is not critical, and the tie rods used in the $2-i n$. section would not be necessary.

- Although glass is slightly soluble in steam, several hours of operation produced no visible deterioration in the optical quality of the glass test-sections.

\section{Acknowledgements}

The author would like to acknowledge the assistance of Jim Kuhlman and Leo Meisner in the design, fabrication, and testing of the spools for the flow-visualization studies. Gary Carter provided the image-enhancement results, and JIm Caywood was the photographer for the st111 and high speed motion-picture coverage. 


\section{References}

1. Y. Taitel and A. E. Dukler, AIChE. J. 22, 47 (1976).

2. 0. Baker, Oil Gas J. 53, 185 (1954).

3. G. F. Hewitt and N. S. Hall-Taylor, Annular Two-Phase Flow (Permagon Press, New York, 1970).

4. G. W. Govier and K. Aziz, The Flow of Complex Mixtures in Pipes (Van Nostrand-Reinhold, New York, 1972).

5. R. Kern, Chem. Eng. (New York) 82, 145 (1975).

6. C. L. Yaws and H. S. N. Setty, Chem. Eng. (New York) 81, 67 (1974).

7. H. Weiss, Geothermal Two-Phase Flow Test Facility, Lawrence Livermore Laboratory, Rept. UCRL-76409, Preprint (1975).

8. A. L. Austin, G. H. Higgins, and J. H. Howard, The Total Flow Concept for Recovery of Energy from Geothermal Hot Brine Deposits, Lawrence Livermore Laboratory, Rept. UCRL-51366 (1973).

9. C. A. Calder, Instrumentation for Two-Phase Geothermal Flow, Lawrence Livermore Laboratory, Rept. UCID-16806 (1975).

10. R. B. McClintock and G. J. Silvestri, CaZculation of Properties of Steam (American Society of Mechanical Engineering, New York, 1968). 